\title{
Educação inclusiva: aspectos históricos, políticos e ideológicos da sua constituição no cenário internacional
}

Educación inclusiva: aspectos históricos, políticos e ideológicos de su constitución en el escenario internacional

Inclusive education: historical, political and ideological aspects of its constitution in the international scenario

\section{Volumen 18, Número 2}

Mayo-Agosto

pp. $1-20$

Daniella de Souza Barbosa

\author{
Lia Machado Fiuza Fialho
}

Charliton José dos Santos Machado

Revista indizada en REDALYC, SCIELO

Revista distribuida en las bases de datos:

\section{LATINDEX, DOAJ, REDIB, IRESIE, CLASE, DIALNET, SHERPA/ROMEO, QUALIS-CAPES, MIAR}

Revista registrada en los directorios:

ULRICH'S, REDIE, RINACE, OEI, MAESTROTECA, PREAL, $\underline{\text { CLACSO }}$ 


\title{
Educação inclusiva: aspectos históricos, políticos e ideológicos da sua constituição no cenário internacional
}

Educación inclusiva: aspectos históricos, políticos e ideológicos de su constitución en el escenario internacional

Inclusive education: historical, political and ideological aspects of its constitution in the international scenario

\section{Daniella de Souza Barbosa ${ }^{1}$ Lia Machado Fiuza Fialho² Charliton José dos Santos Machado 3}

\begin{abstract}
Resumo: O imperativo ético de garantia de direitos humanos e igualdade às pessoas com deficiência, por intermédio da Educação Inclusiva, é paradigma relativamente recente no cenário brasileiro e sua efetivação é complexa. Objetiva-se desenvolver uma pesquisa histórica, do tipo documental, a respeito das políticas públicas internacionais de Educação Especial com ênfase nas mudanças paradigmáticas emergentes cronologicamente no Brasil. Conclui-se que os séculos XVIII e XIX foram marcados pela segregação homogeneizante das pessoas com deficiência em escolas especiais e que, a partir do século XX, impulsionadas por documentos internacionais, emergem as classes especiais superadas pela ideologia atual de igualdade e inclusão social com respeito às diferenças que possibilita não apenas a inclusão na escola regular, mas mecanismos de luta para igualdade de condições. As reflexões ensejam que acordos internacionais impulsionam o Brasil a alinhar sua política interna em direção à garantia de direitos humanos e igualdade às pessoas com deficiência.
\end{abstract}

Palavras-chave: educação inclusiva, pessoas com deficiência, educação especial.

Resumen: El imperativo ético que permite garantizar derechos humanos e igualdad a las personas con discapacidad por intermedio de la Educación Inclusiva es un paradigma relativamente reciente en el escenario brasileño y su efectividad es compleja. Se pretende desarrollar una investigación histórica, del tipo documental, respecto a las políticas públicas internacionales de Educación Especial con énfasis en los cambios paradigmáticos emergentes cronológicamente en Brasil. Se concluye que los siglos XVIII y XIX fueron marcados por la segregación homogeneizante de las personas con discapacidad en escuelas especiales y que, a partir del siglo XX, impulsadas por documentos internacionales, emergieron las clases especiales superadas por la ideología actual de igualdad e inclusión social con respecto a las diferencias que posibilita no solo la inclusión en la escuela regular, sino mecanismos de lucha para la igualdad de condiciones. Las reflexiones plantean que acuerdos internacionales impulsan el Brasil a alinear su política interna hacia la garantía de derechos humanos y de igualdad a las personas con discapacidad.

Palabras clave: educación inclusiva, personas con discapacidad, educación especial.

\footnotetext{
1 Professora doutora da Faculdade Maurício de Nassau, Brasil, no Curso de Graduação em Fisioterapia e professora adjunta da Faculdade de Ciências Médicas da Paraíba. Professora visitante do Curso de Especialização em Atendimento Educacional Especializado da Faculdade Integrada de Patos (FIP) entre 2015 e 2016. Endereço eletrônico: daniellafcm@hotmail.com

2 Professora doutora do Centro de Educação e do Programa de Pós-Graduação em Educação da Universidade Estadual do Ceará (UECE), Brasil. Endereço eletrônico: liafialho@yahoo.com.br

${ }^{3}$ Professor doutor associado IV e professor permanente dos Programas de PósGraduação em Educação (PPGE) e em Sociologia (PPGS), ambos da Universidade Federal da Paraíba (UFPB), Brasil. Endereço eletrônico: charlitonlara@yahoo.com.br
}

Ensayo recibido: 10 de noviembre, 2017

Enviado a corrección: 13 de marzo, 2018

Aprobado: 9 de abril, 2018 


\begin{abstract}
The ethical imperative that guarantees human rights and equality for people with disabilities through Inclusive Education is a relatively recent paradigm in Brazilian scenario and its implementation is complex. The objective is to develop a historical, documentary-type research, a path on international public policies of Special Education with emphasis on paradigmatic changes emerging chronologically in Brazil. It is concluded that the eighteenth and nineteenth centuries were marked by the homogenizing segregation of people with disabilities in special schools and that, from the twentieth century onwards; special classes emerged, driven by international documents. Such classes were overcome the current ideology of equality and social inclusion towards the differences that make possible not only the inclusion in the regular school, but some mechanisms to fight for equality of conditions. The reflections show that the international discussions and agreements impel Brazil to align its internal policy towards the guarantee of human rights and equality for people with disabilities.
\end{abstract}

Keywords: inclusive education, people with disabilities, special education.

\title{
1. Introdução
}

A compreensão dos aspectos históricos, políticos e ideológicos da Educação Inclusiva, como modelo transversal de ensino que dialoga e compartilha os mesmos princípios e práticas da Educação geral, é recente no cenário brasileiro e exige de seus sujeitos escolares uma reflexão sobre a complexidade desse novo imperativo ético, o qual busca garantir os direitos humanos de populações historicamente excluídas dos espaços sociais, como a escola. Igualmente recentes são os estudos sobre as mudanças de paradigmas provocadas por essa ação afirmativa ao longo dos tempos nas políticas públicas educacionais no Brasil.

Questionam-se como as políticas públicas veiculadas em documentos oficiais de organismos internacionais - Organização das Nações Unidas (ONU), Organização das Nações Unidas para a Educação, a Ciência e a Cultura (Unesco), Organização dos Estados Americanos (OEA), Fundo das Nações Unidas para a Infância (Unicef) e Banco Mundial (BM) - influíram para mudança de compreensão acerca do paradigma segregativo na Educação Inclusiva brasileira. Para compreender como foi se constituindo a compreensão de Educação Inclusiva ao longo dos tempos, influenciada pelos organismos internacionais que lançaram bases ideológicas nos documentos legais brasileiros, desenvolveu-se uma pesquisa no campo da História da Educação, com objetivo de desenvolver um histórico a respeito das políticas públicas internacionais de Educação Especial com ênfase nas mudanças paradigmáticas emergentes cronologicamente no Brasil.

Metodologicamente, realizou-se, no primeiro semestre do ano de 2017, uma pesquisa de abordagem qualitativa, de cunho histórico, do tipo documental, com base em textos internacionais produzidos no seio dos debates sobre a Educação Inclusiva, em especial sobre os direitos da pessoa com deficiência, tais como: 1) Convenção Interamericana para a Eliminação de Todas as Formas de Discriminação contra as Pessoas Portadoras de 
Deficiência; 2) Declaração Universal dos Direitos Humanos; 3) A Unesco e a Educação na América Latina e Caribe; 4) Educação para Todos: o compromisso de Dakar; 5) A Unesco no Brasil: consolidando compromissos; 6) Conferência Mundial de Necessidades Educativas Especiais: Acesso e Qualidade.

Salienta-se que a Educação Especial é uma área do conhecimento relativamente nova no campo da Educação brasileira, tendo em vista que foi incluída no currículo dos cursos de Pedagogia somente a partir do século XIX, como resposta da academia às demandas das instituições assistenciais filantrópicas privadas, que, mesmo situadas à margem dos sistemas de ensino, já prestavam atendimento educacional às pessoas "excepcionais" desde o século XVIII, isto é, àquelas com deficiências sensoriais como a surdez e a cegueira, por exemplo.

Nesse sentido, a Educação Especial nasceu sob o paradigma segregacionista de Educação que tentava produzir uma reparação histórica frente aos processos de exclusão escolar sofridos pelas pessoas que apresentavam singularidades sensoriais e, em seguida, por aquelas ditas "idiotas" ou "imbecis" (atualmente denominadas de pessoas com deficiência intelectual).

$\mathrm{Na}$ condição de temática emergente nos debates internacionais, a Educação Especial vem galgando novos contornos que problematizam a visão essencialmente homogeneizante e segregacionista, proporcionando o rompimento de paradigmas históricos e o fomento de uma ideologia pautada na inclusão. Defende-se, pois, a tese de que os debates internacionais registrados em documentos oficiais impulsionam mudanças de concepções e, consecutivamente, de políticas impulsionando o Brasil a alinhar sua política interna em direção à garantia de direitos humanos e igualdade às pessoas com deficiência

Importa, portanto, historicizar a respeito das políticas públicas de Educação Especial no cenário internacional, com ênfase nos avanços emergentes de debates universais nos séculos XX e XXI, a fim de clarificar compreensões sobre ideologias, propostas de inclusão e ações em desenvolvimento, com vistas à inclusão da pessoa com deficiência nos espaços e tempos da escola regular no Brasil.

\section{História da Educação Especial: o contexto brasileiro}

A base filosófico-ideológica que persistiu no cenário internacional entre os séculos XVIII e XIX foi a do modelo escolar segregacionista, baseado na homogeneização das pessoas de acordo com suas características biológicas - concepção organicista. Esse 
paradigma preconizava como resposta educacional às necessidades de escolarização das crianças "excepcionais" a sua institucionalização em "escolas especiais", pressupondo a deficiência como um fenômeno hereditário com evidências de degenerescência da espécie humana (Mendes, 1995). Assim, a segregação era considerada a melhor forma de se combater a ameaça representada por essa população à sociedade (Dechichi, 2001).

Em suma, os alunos eram rotulados como "excepcionais", ou seja, havia uma visão patológica da deficiência, o que contribuía para a marginalização do aluno no sistema regular de ensino no Brasil e sua consequente institucionalização em espaços escolares de caráter assistencial, tendo em vista que a deficiência era vista como causa e consequência do baixo rendimento escolar dessas pessoas, o que justificava, teoricamente, sua segregação em espaços escolares entendidos como capazes de "curar" ou "eliminar" a deficiência por meio da Educação (Voivodic, 2004).

A partir do final do século XIX e início do século XX, foi percebido que o atendimento educacional das pessoas com deficiência era também um problema do Estado e da rede regular de ensino, sendo necessária a organização de um modelo de escola pública capaz de acolher os alunos "portadores de necessidades especiais", surgindo, assim, as "escolas especiais" públicas ou a instalação de "classes especiais" nas já existentes, que visavam oferecer à pessoa "deficiente" uma Educação à parte. Emerge nesse cenário brasileiro o paradigma da integração instrucional, no qual os discentes com deficiência - seja física, sensorial ou intelectual - poderiam se matricular em salas de aula comuns se possuíssem condições de acompanhar e desenvolver, no mesmo ritmo dos estudantes ditos "normais", as atividades curriculares programadas para o ensino comum. No entanto, aqueles que possuíssem rendimento escolar abaixo da média estipulada pelo sistema de ensino continuavam segredados da rede regular e sua matrícula se limitava às "escolas especiais".

Nesse período histórico, a normalização das condutas de participação e aprendizagem dos educandos "portadores de necessidades especiais" foi definida como o princípio que representava a base filosófico-ideológica do modelo de integração instrucional. Vale frisar que nesse caso não se tratava de "normalizar" esses alunos, mas sim o contexto em que se desenvolviam, em outras palavras, tinha-se como intuito oferecer aos aprendizes com deficiência condições de vida diária o mais semelhante possível às formas e condições de vida do restante da sociedade.

A Educação Especial no cenário mundial passou de uma concepção organicista para uma abordagem funcional. A primeira concebia a deficiência como consequência de 
características biológicas e utilizava-se da estratégia de segregação dos "excepcionais" em instituições assistenciais filantrópicas da rede privada de ensino. A segunda, por sua vez, definia a deficiência em função das capacidades e habilidades funcionais residuais e empregava a estratégia da integração das pessoas "portadoras de necessidades especiais" em "escolas especiais" ou em "classes especiais" da rede pública de ensino, a fim de estabelecer interações sociais entre esses educandos e os alunos ditos "normais" (Rioux e Valentine, 2006).

Mesmo com essa evolução filosófico-ideológica em torno dos objetivos e qualidade dos serviços educacionais especiais, a Educação Especial no Brasil continuava negligenciada pelos sistemas regulares de ensino, tendo em vista que essa modalidade de ensino ainda era tida como substitutiva do processo de escolarização das pessoas historicamente marginalizadas da escola comum. Seja pela homogeneização - processo de exclusão fora da escola -, seja pela normalização - procedimento de exclusão dentro da escola -, a era da exclusão dessa população persistia no cenário das reformas educacionais gerais desde 0 século XVIII até meados do século XX, pois não havia a preocupação político-pedagógica de incluir a pauta da Educação Especial no desenvolvimento dos sistemas regulares de ensino brasileiro (Sánchez, 2005).

Ainda que sob formas distintas, a exclusão tem sido característica recorrente na Educação fomentada no Brasil. No paradigma segregacionista, as pessoas com deficiência estão inseridas em escolas especiais; e as pessoas sem deficiência, no ensino regular. No âmbito da integração escolar, as pessoas com deficiência estão na mesma instituição de ensino que as pessoas sem deficiência, mas em grupos separados por "classes especiais", o que pressupõe a Educação Especial como modalidade de ensino substitutiva do processo de escolarização desses alunos, cujo resultado foi a naturalização do fracasso escolar (Sánchez, 2005).

A partir da segunda metade do século $X X$, emergiu com maior ênfase, no cenário mundial, a defesa do paradigma da inclusão como uma ação política, cultural, social e pedagógica, desencadeada em defesa dos direitos de todos os estudantes de estarem aprendendo e participando juntos, sem nenhum tipo de discriminação. Essa concepção fundamentava-se na base filosófico-ideológica que defendia a garantia dos direitos humanos e, ao mesmo tempo, "[...] conjuga[va] igualdade e diferença como valores indissociáveis, e que avança[va] em relação à idéia [sic] de eqüidade [sic] formal ao contextualizar as 
circunstâncias históricas da produção da exclusão dentro e fora da escola" (Ministério da Educação. Secretaria de Educação Especial, Brasil, 2008, p. 5).

No decorrer do período da era da inclusão no Brasil, fortaleceu-se a crítica às práticas de conceituação, identificação e categorização dos discentes encaminhados para ambientes escolares "especiais" sob o signo da abordagem da deficiência como uma patologia individual capaz de determinar o fracasso escolar de seus "portadores". Além disso, criticavase o cunho assistencialista dessa política, em que a instituição privada com fins filantrópicos tinha caráter de internato e as pessoas com deficiência eram retiradas do convívio familiar e social para viverem em instituições asilares. Dentro de uma visão biomédica, entendia-se que a responsabilidade social da Educação Especial era a de curar ou eliminar a deficiência de seus alunos por meio da Educação.

O movimento mundial pela inclusão escolar conduziu o debate sobre a Educação Especial ao questionamento dos modelos de normalização de ensino e de aprendizagem, geradores de exclusão nos espaços escolares regulares sob o símbolo da integração instrucional, que instituía "classes especiais" na rede regular de ensino, notadamente no sistema público. Nesse modelo, a Educação de "portadores de necessidades especiais" deveria, no que fosse possível, enquadrar-se ao sistema geral de educação, a fim de integrálos à comunidade. Desse modo, em vez de a escola ter que se adequar às necessidades físicas, sensoriais, intelectuais, sociais e culturais do discente, este é que deveria se adequar à escola, em termos de estrutura física, pedagógica e administrativa.

Portanto, os tempos, espaços, práticas e saberes escolares na área de conhecimento da Educação Especial, no Brasil, historicamente, se caracterizaram pela visão da Educação que entendia a escolarização como um privilégio de um grupo dito "normal" e a exclusão dentro e fora da escola - como estratégia para o tratamento das pessoas ditas "deficientes". Esse entendimento foi legitimado nas políticas e práticas educacionais "especiais", reprodutoras das relações sociais e de poder, que classificavam os grupos humanos de maneira subalterna uns aos outros, transformando as naturais diferenças humanas em desigualdades e injustiças sociais (Sassaki, 2005).

\section{Marcos legal e políticos internacionais de Educação Inclusiva e a repercussão no Brasil}

A análise documental, dos seis textos legais - 1)Convenção Interamericana para a Eliminação de Todas as Formas de Discriminação contra as Pessoas Portadoras de 
Deficiência; 2)Declaração Universal dos Direitos Humanos; 3)A Unesco e a Educação na América Latina e Caribe; 4)Educação para Todos: o compromisso de Dakar; 5)A Unesco no Brasil: consolidando compromissos; 6)Conferência Mundial de Necessidades Educativas Especiais: Acesso e Qualidade, - permitiu inferir que sob a era da inclusão, no paradigma veiculado pelos documentos oficiais internacionais, a deficiência passa a ser tratada internacionalmente na perspectiva da abordagem dos direitos humanos, ou seja, como uma patologia social produzida em consequência da organização social e da relação entre 0 indivíduo e a sociedade, cuja responsabilidade sobre essas pessoas singulares seria por meio da reconstrução de políticas públicas de Educação Especial, entendidas como ações afirmativas em defesa da diferença e da diversidade humana, visando à superação dessas mesmas desigualdades e injustiças através da eliminação de práticas pedagógicas discriminatórias e excludentes (Sassaki, 2005). Nessa vertente, prima-se pela oferta de um atendimento educacional especializado de modo complementar ou suplementar ao processo de escolarização desses alunos, sendo ambos os serviços disponibilizados no espaço comum da escola regular.

Logo, a partir da década de 1990, o movimento educacional internacional pela inclusão, que preconizava que todas as pessoas deveriam estar inseridas nos mesmos espaços e tempos escolares, passou a integrar a pauta obrigatória na escola no Brasil, enfatizando-se especialmente o tema sobre as mais eficientes formas de atendimento educacional especializado e sobre a escolarização dos alunos público-alvo da Educação Especial no sistema regular de ensino. Com efeito, passa-se a discutir a garantia do direito à Educação das pessoas com deficiência, transtorno global do desenvolvimento e com altas habilidades/superdotação, segundo os marcos legais, políticos e pedagógicos promulgados por organismos internacionais, como a ONU.

Dentro desse processo de evolução histórica das políticas públicas no cenário brasileiro, a modalidade de ensino da Educação Especial passou, sob o verniz ético-político da Educação Inclusiva, a garantir 0 acesso, a permanência, a participação e 0 desenvolvimento acadêmico e social dos estudantes público-alvo do Atendimento Educacional Especializado (AEE) na escola comum a partir da tentativa de eliminação das barreiras pedagógicas, arquitetônicas, comunicacionais e atitudinais. Afinal, os documentos internacionais defendem que não é o limite individual que determina a deficiência, mas sim as barreiras existentes nos espaços, no meio físico, no transporte, na informação, na 
comunicação e nos serviços. A escola, nessa vertente, deve tornar-se um espaço acolhedor das diferenças.

A elaboração dos direitos que asseguram a participação de todos e a efetivação de uma sociedade inclusiva fica patente a partir de 10 de dezembro de 1948, quando da elaboração da Declaração Universal dos Direitos Humanos pela Assembleia Geral das Nações Unidas, que se fundamenta no reconhecimento da dignidade de todas as pessoas e na universalidade e indivisibilidade desses direitos e, portanto, no valor da diversidade humana que se impõe como condição para o alcance de tal reconhecimento ao explicitar a pessoa como sujeito de direito, respeitado em suas peculiaridades e particularidades. Como garantia do direito à Educação, a citada declaração internacional normatiza:

Art. 26. 1. Todo ser humano tem direito à instrução. A instrução será gratuita, pelo menos nos graus elementares e fundamentais. A instrução elementar será obrigatória. A instrução técnico-profissional será acessível a todos, bem como a instrução superior, está baseada no mérito. 2. A instrução será orientada no sentido do pleno desenvolvimento da personalidade humana e do fortalecimento do respeito pelos direitos humanos e pelas liberdades fundamentais. A instrução promoverá a compreensão, a tolerância e a amizade entre todas as nações e grupos raciais ou religiosos e coadjuvará as atividades das Nações Unidas em prol da manutenção da paz. 3. Os pais têm prioridade de direito na escolha do gênero de instrução que será ministrada a seus filhos. (ONU, 1948, p. 5)

Tal declaração parece não gerar mudanças significativas na forma de oferta e compreensão acerca da educação inclusiva. Quase 30 anos depois dessa primeira publicação, em 9 de dezembro de 1975, a ONU (1975, p. 2) abordou especificamente a temática da inclusão, ao lançar a Declaração dos Direitos das Pessoas Deficientes ${ }^{4}$, que assevera:

As pessoas deficientes têm direito a tratamento médico, psicológico e funcional, incluindo-se aí aparelhos protéticos e ortóticos, à reabilitação médica e social, educação, treinamento vocacional e reabilitação, assistência, aconselhamento, serviços de colocação e outros serviços que lhes possibilitem o máximo

\footnotetext{
4 “O termo 'pessoas deficientes' refere-se a qualquer pessoa incapaz de assegurar por si mesma, total ou parcialmente, as necessidades de uma vida individual ou social normal, em decorrência de uma deficiência, congênita ou não, em suas capacidades físicas ou mentais" (ONU, 1975, p. 1).
} 
desenvolvimento de sua capacidade e habilidades e que acelerem o processo de sua integração social.

A partir da década de 1980, o Brasil, país signatário, impulsionado por debates internacionais, buscou afirmação do direito à Educação das pessoas público-alvo da Educação Especial por meio da realização de conferências sobre o tema da inclusão escolar constituídas por organismos nacionais e internacionais de defesa dos direitos humanos. Ademais, ratificaram-se algumas declarações sobre as demandas específicas dessa área de conhecimento que precisavam ser legitimadas democraticamente mediante instrumentos jurídicos locais e de princípios aplicáveis a cada país-membro.

No ano de 1981, por exemplo, foram promulgados dois documentos relevantes para a Educação Especial, a saber: a Declaração de Cuenca sobre novas tendências na Educação Especial (Unesco/Orealc - Cuenca, Equador), que recomendava a eliminação de barreiras físicas e a participação de pessoas "deficientes" na tomada de decisões a seu respeito; e a Declaração de Sunderberg como resultado da Conferência Mundial sobre as Ações e Estratégias para a Educação, Prevenção e Integração dos Impedidos (Unesco Torremolinos, Espanha), cujo tema principal era a equiparação de oportunidades das pessoas "deficientes” à Educação, formação, cultura e informação (Carvalho, 2002).

A década de 1980 marcou o Brasil, pois deu início ao debate mais acirrado para estimular o cumprimento dos direitos das pessoas "deficientes" à Educação, à saúde e ao trabalho. Em 1981, comemorou-se em todo o mundo o Ano Internacional das Pessoas Deficientes, proclamado pela Assembleia Geral das Nações Unidas ${ }^{5}$, cujo lema foi participação plena e igualdade, em que a ONU oficializou o embrião do conceito de sociedade inclusiva. Partindo da ideia de que as pessoas "deficientes" formam parte da sociedade e não são uma sociedade à parte, o Ministério da Educação e Cultura (MEC) do Brasil, em consonância com a citada resolução da ONU, traçou as seguintes ações a curto, médio e longo prazo para a oferta do AEE em território nacional:

I - Curto Prazo: 1) Estabelecer modelos para serviços de atendimento educacional; 2) Organizar seminários e congressos a nível nacional sobre Educação Especial; 3) Fomentar o desenvolvimento de recursos humanos em Educação Especial a nível de $2^{\circ}$ Grau; 4) Sensibilizar os Conselhos de Educação ${ }^{\circ}$ (Estaduais e Federal) para os

5 "Em sua trigésima sessão, de 16 de dezembro de 1976, a Assembleia Geral das Nações Unidas, pela Resolução no 31/123, proclamou, oficialmente, o ano de 1981 como o Ano Internacional das Pessoas Deficientes" (ONU, 1981, p. 6). 
problemas da Educação Especial; 5) Assessorar a Secom sobre a publicação de material informativo sobre multiplicidade de ações implícitas na Educação Especial; 6) Promover o levantamento de todo o material bibliográfico sobre Educação Especial; 7) Ampliar e reestruturar o atendimento pré-escolar do Instituto Nacional de Educação de Surdos - Ines - e do Instituto Benjamin Constant - IBC -, visando transformá-los em serviços-modelo; 8) Aperfeiçoar e ampliar programa de bolsa de trabalho para educandos deficientes; 9) Publicar documentos relativos à Educação Especial elaborados pelo Cenesp; 10) Aperfeiçoar e ampliar o projeto de Assistência Técnica às Secretarias Estaduais de Educação. II - Médio Prazo: 1) Estimular a formação de técnicos especializados a nível de $3^{\circ}$ Grau; 2) Elaborar o II Plano Nacional de Educação Especial; 3) Normalização da Educação Física para deficientes; 4) Efetuar estudos sobre estatística da Educação Especial; 5) Implementar a modernização da Imprensa Braille. III - Longo Prazo: 1) Estimular, nos Estados e Municípios, a criação de serviços de atendimento educacional que objetivem a integração e a normalização; 2) Criar centros de produção de material psicopedagógico; 3) Elaborar o I Plano Nacional Integrado de Assistência ao Excepcional; e 4) Estimular a Educação Especial de deficientes adultos. (ONU, 1981, pp. 14-15)

Uma importante consequência do Ano Internacional das Pessoas Deficientes (1981) foi a aprovação do Programa Mundial de Ação relativo às Pessoas com Deficiência pela Assembleia Geral da ONU, por meio da Resolução nํ37/52, de 3 de dezembro de 1982. Prontamente, o Ano Internacional e o Programa Mundial de Ação contribuíram para um forte desenvolvimento nesse domínio, por intermédio da criação da Década das Nações Unidas para as Pessoas com Deficiência (1983-1992), que visava garantir às pessoas com deficiência o exercício dos seus direitos fundamentais e a sua participação plena na sociedade (ONU, 1993). Ambos salientavam o direito das pessoas "deficientes" às mesmas oportunidades de que gozavam os demais cidadãos, visando a todos melhores condições de vida resultantes do desenvolvimento econômico e social de suas comunidades (Unesco, 1990).

Aspirando a enfrentar esse desafio mundial e a construir projetos capazes de superar os processos históricos de exclusão escolar dessas pessoas, com base na responsabilidade comum e universal de todos os povos, a Unesco estabeleceu a Conferência Mundial de Educação para Todos, realizada em Jomtien, na Tailândia, no período de 5 a 9 de março de 1990. Esse evento implicou a solidariedade internacional dos organismos e instituições 
intergovernamentais a fim de satisfazer as necessidades básicas de aprendizagem de seus cidadãos, haja vista os altos índices de crianças, adolescentes e jovens sem escolarização. Somente assim seria possível promover as transformações nos sistemas de ensino para assegurar o acesso e a permanência de todos na escola (Unesco, 1990).

Os principais referenciais da Declaração de Jomtien $(1990)^{6}$ publicados no ano seguinte pelo Unicef enfatizavam a urgência de uma Educação de qualidade para todos, ao constituírem a agenda de discussão das políticas educacionais, reforçando: a necessidade de elaboração e a implementação de ações voltadas para a universalização do acesso à escola; a promoção da equidade no âmbito do ensino fundamental, médio e superior; a oferta da Educação Infantil nas redes públicas de ensino; a estruturação do atendimento às demandas de alfabetização e da modalidade de Educação de Jovens e Adultos; e a construção da gestão democrática da escola. Sob a perspectiva inclusiva, a referida declaração, nos itens 4 e 5 do artigo $3^{\circ}$, instituiu que:

4. Um compromisso efetivo para superar as disparidades educacionais deve ser assumido. Os grupos excluídos - os pobres; os meninos e meninas de rua ou trabalhadores; as populações das periferias urbanas e zonas rurais; os nômades e os trabalhadores migrantes; os povos indígenas; as minorias étnicas, raciais e lingüísticas [sic]; os refugiados; os deslocados pela guerra; e os povos submetidos a um regime de ocupação - não devem sofrer qualquer tipo de discriminação no acesso às oportunidades educacionais. 5. As necessidades básicas de aprendizagem das pessoas portadoras de deficiências requerem atenção especial. É preciso tomar medidas que garantam a igualdade de acesso à educação aos portadores de todo e qualquer tipo de deficiência, como parte integrante do sistema educativo. (Unesco, 1990, p. 4)

Vale lembrar que as diversas declarações da ONU culminaram, em 1993, na publicação das Normas sobre a Igualdade de Oportunidades ${ }^{7}$ para as Pessoas com Deficiência, por meio de resolução das Nações Unidas, adotada pela Assembleia Geral no dia 20 de dezembro de 1993. As normas exortavam os Estados, dentre eles o Brasil, a assumirem um compromisso ético e político, com vistas a operacionalizar, dentre outros direitos, o acesso ao sistema

6 No Brasil, o MEC divulgou o Plano Decenal de Educação para Todos, para o período de 1993 a 2003 , elaborado em cumprimento às resoluções da Declaração de Jomtien (1990).

7 "O termo 'igualdade de oportunidades' significa o processo pelo qual os diversos sistemas da sociedade e o meio envolvente, tais como serviços, atividades, informação e documentação, se [sic] tornam acessíveis a todos e, em especial, às pessoas com deficiência" (ONU, 1993, p. 16). 
regular de ensino às pessoas com deficiência em igualdade de oportunidades com as demais pessoas, independentemente da natureza e gravidade da sua deficiência, tendo como estratégias complementares as escolas especiais (ONU, 1993).

Por conseguinte, a tendência dos organismos internacionais atrelados ao desenvolvimento da Educação em seus países-membros, notadamente aqueles ligados à ONU durante as décadas de 1980 e 1990, tinha sido a de promover integração e participação, além de combater a exclusão dos grupos socialmente marginalizados, como era o caso das pessoas "deficientes". O paradigma da inclusão surgiu mais enfaticamente com a Declaração de Jomtien (1990), no contexto do movimento político mundial para o fomento de uma agenda internacional em prol do alcance das metas do direito à Educação das pessoas com deficiência nos sistemas regulares de ensino. Seu ápice, no entanto, ocorreu com a produção de um documento publicado pelo Governo da Espanha em parceria com a Unesco entre os dias 7 e 10 de junho de 1994, denominado Declaração de Salamanca sobre os princípios, a política e as práticas na área das necessidades educativas especiais $^{8}$, como resultado da Conferência Mundial de Necessidades Educativas Especiais: Acesso e Qualidade.

Tal Declaração teve a finalidade de promover o objetivo da Educação para Todos, ou seja, da Educação Especial sob a perspectiva da Educação Inclusiva, examinando as mudanças fundamentais das políticas públicas educacionais necessárias para desenvolver tal abordagem, nomeadamente qualificando as escolas regulares para atender a todas as crianças, sobretudo as que têm necessidades educativas especiais, de modo que os governos, com apoio das organizações internacionais, pudessem conceder maior prioridade ao desenvolvimento de seus respectivos Sistemas Nacionais de Educação, sob a perspectiva inclusiva, através de medidas políticas e orçamentárias compatíveis com esse imperativo ético (Unesco, 1994).

A partir dessa reflexão acerca das práticas educacionais especiais, da qual resultaram a compreensão de equiparação de oportunidades de diversos grupos sociais (crianças com deficiência e crianças bem dotadas; crianças que vivem nas ruas e que trabalham; crianças de populações distantes ou nômades; crianças de minorias linguísticas, étnicas ou culturais e crianças de outros grupos e zonas desfavorecidas ou marginalizadas), a Declaração de Salamanca e Linha de Ação sobre Necessidades Educativas Especiais proclamou que as

8 A expressão "necessidades educativas especiais", no citado documento, refere-se a todas as crianças e jovens cujas carências se relacionam com deficiências ou dificuldades escolares, incluindo nesse escopo as pessoas com deficiência e as superdotadas (UNESCO, 1994). 
escolas comuns representavam o meio mais eficaz para combater as atitudes discriminatórias, ressaltando que o princípio fundamental dessa linha de ação seria o de que as escolas inclusivas deveriam acolher todas as crianças, independentemente de suas condições físicas, intelectuais, sociais, emocionais, linguísticas ou outras (Unesco, 1994).

$\mathrm{Na}$ esteira de construção de uma agenda internacional em torno da promoção de uma Educação para Todos, em particular para aquelas com necessidades educacionais especiais, capazes de gerar diversos instrumentos e recomendações internacionais passíveis de serem incorporados ao sistema jurídico dos países-membros de organismos internacionais ligados ao fomento da Educação, tornando-os internamente obrigatórios, surgiram outros movimentos sociais em torno da proposta da inclusão escolar, como: a Declaração de Cartagena de Índias, as Políticas Integrais para Pessoas com Deficiências na Região Ibero-Americana na Colômbia em 1992; a Conferência Hemisférica de Pessoas com Deficiências em Washington/EUA em 1993; a 5 $5^{\text {a }}$ Reunião do Comitê Regional Intergovernamental do Projeto Principal de Educação na América Latina e Caribe, que resultou na Declaração de Santiago, realizada no Chile em 1993; a 1a Reunião dos Participantes da Conferência de Ministros responsáveis pela situação da pessoa com deficiência, ocorrida em Montreal/Canadá em 1994; e a publicação das normas uniformes sobre a igualdade de oportunidades para pessoas com deficiência, aprovadas pela Assembleia Geral nำ48/96, de 20 de dezembro de 1993, da ONU.

Por fim, a construção do cenário internacional da Educação Especial, sob o aspecto filosófico-ideológico da inclusão na década de 1990, culminou com a Convenção Interamericana para a Eliminação de Todas as Formas de Discriminação contra as Pessoas Portadoras de Deficiência ${ }^{9}$, mais conhecida como Convenção da Guatemala, aprovada pelo Conselho Permanente da OEA na sessão realizada em 26 de maio de 1999, no país da América Central supracitado, promulgada no Brasil pelo Decreto no 3.956/2001. Esse documento, que ainda utilizava a expressão "portador de deficiência", afirmava que os Estados-Partes deveriam se comprometer a tomar as medidas de caráter legislativo, social, educacional, trabalhista, ou de qualquer outra natureza, que fossem necessárias para eliminar a discriminação contra as pessoas "portadoras de deficiência" e proporcionar a sua plena "integração" à sociedade.

9 "[...] o termo 'discriminação contra as pessoas portadoras de deficiência' significa toda diferenciação, exclusão ou restrição baseada em deficiência, antecedente de deficiência, conseqüência [sic] de deficiência anterior ou percepção de deficiência presente ou passada, que tenha o efeito ou propósito de impedir ou anular o reconhecimento, gozo ou exercício por parte das pessoas portadoras de deficiência de seus direitos humanos e suas liberdades fundamentais" (OEA, 1999, p. 3). 
Tendo em vista o protagonismo das agências e organizações intergovernamentais no panorama mundial, como a ONU e suas agências especializadas (Unesco, Unicef e BM), e no cenário regional, como a OEA, na busca pela cooperação internacional a fim de promover e estimular, entre seus países-membros, o respeito aos direitos humanos e às liberdades fundamentais para todos, especialmente entre os grupos minoritários, como no caso da melhoria das condições de vida para pessoas com deficiência, verificou-se que o percurso histórico, político e filosófico da Educação Especial nos anos 1990 culminou no paradigma inclusivo de garantia da equiparação de oportunidades, direitos e deveres de seu público-alvo no interior do sistema regular de ensino (Peroni, 2003).

Em pleno anos 2000, a ONU continuou a fixar padrões, a trabalhar para tecer consensos universais e a manter-se como um fórum central disseminador para a comunidade internacional de princípios e orientações gerais para a Educação, através de sua agência especializada da Unesco. Ademais, seguiu lançando as diretrizes sobre os caminhos da Educação Especial através de declarações e recomendações acordadas para a construção das políticas públicas educacionais inclusivas ao redor do mundo. Dessa forma, entre os dias 26 e 28 de abril de 2000, em Dakar, Senegal, 164 países reuniram-se no Fórum Consultivo Internacional para a Educação para Todos, criado em 1991 e composto por representantes da Unesco, Unicef e BM, contando com agências bilaterais, governos e sociedade civil, para avaliar os progressos globais alcançados desde a Conferência Mundial de Educação para Todos, realizada dez anos antes em Jomtien, Tailândia, e para aprovar novo marco de ação para a universalização da Educação Básica (Unesco, 2001).

Em 13 de dezembro de 2006, em sessão solene da Assembleia Geral da ONU, foi aprovado o texto final da Convenção sobre os Direitos das Pessoas com Deficiência ${ }^{10}$, firmado pelo Brasil e por mais 85 nações signatárias em 30 de março de 2007. Esse tratado internacional, no que diz respeito ao direito à Educação aos deficientes, estabelece que os Estados-Partes devem assegurar um sistema de Educação Inclusiva em todos os níveis de ensino, bem como o aprendizado ao longo da vida. Em seu artigo 24, determina que as pessoas com deficiência não sejam excluídas do sistema educacional geral e que as crianças com deficiência não sejam excluídas do ensino fundamental gratuito e compulsório; estabelece também que elas tenham acesso ao ensino médio e superior inclusivo, de

\footnotetext{
10 Nesse texto a ONU reconhece que "[...] a deficiência é um conceito em evolução e que a deficiência resulta da interação entre pessoas com deficiência e as barreiras atitudinais e ambientais que impedem sua plena e efetiva participação na sociedade em igualdade de oportunidades com as demais pessoas" (ONU, 2012, p. 22).
} 
qualidade e gratuito, em igualdade de condições com as demais pessoas na comunidade em que vivem (ONU, 2012).

Ainda no panorama internacional, a Unesco lança em 2009 uma coletânea intitulada Orientações Políticas sobre Inclusão na Educação a fim de ampliar a compreensão das questões atinentes às políticas e às práticas pedagógicas que visam garantir a inclusão educacional e social. Os dados apresentados e as análises feitas suscitaram questionamentos e posicionamentos em relação às condições de acesso e de atendimento nas redes de ensino e possibilitaram o aprofundamento do debate sobre as ações do poder público e da sociedade com vistas a assegurar o direito de todas as pessoas à Educação Escolar de Qualidade (No cenário regional da América Latina e do Caribe, houve, em 2009, a Campanha Latino-Americana pelo Direito à Educação, a fim de promover o desenvolvimento de pesquisas interdisciplinares para subsidiar a formulação de políticas públicas intersetoriais que atendessem às especificidades educacionais de estudantes com deficiência, transtornos globais do desenvolvimento e altas habilidades ou superdotação que requeiram medidas de atendimento especializado. Já na União Europeia, a Agência Europeia para o Desenvolvimento da Educação Especial recomendou, também em 2009, para decisórios políticos, princípios básicos para a Promoção da Qualidade na Educação Inclusiva. Fávero, Ferreira, Ireland e Barreiros, 2009).

A influência histórica, direta ou indireta, das agências internacionais no direcionamento das políticas públicas, dentre elas a Educação Especial, situada no âmbito geral das diretrizes da Educação como um direito de todos e dever do Estado, implica o entendimento de que os fundamentos ideológicos que dão sustentação às políticas educacionais na área de conhecimento da Educação Especial adotadas pelos governos brasileiros certamente não foram gerados exclusivamente em âmbito nacional, mas, ao contrário, em âmbito internacional, vinculados às declarações e recomendações construídas em foros de abrangência mundial e regional. Em consequência, torna-se obrigatório considerar que a atuação das Nações Unidas teve papel preponderante para a internacionalização do discurso da Educação Especial na perspectiva da Educação Inclusiva nos anos 1990 e 2000, notadamente pelo trabalho técnico-político da Unesco.

$\mathrm{Na}$ perspectiva da citada agência intergovernamental, atuar nessa agenda de cooperação internacional e nacional com os Estados-Partes na formulação de políticas e estratégias destinadas ao melhoramento dos sistemas de ensino "[...] significa avançar para uma sociedade educacional, onde cada pessoa aprenda durante toda a vida e seja fonte de 
aprendizagem para os demais" (Unesco, 1998, p. 11), afinal a "[...] educação desempenha um papel chave neste processo, tendo em vista o seu valor econômico e social" (Unesco, 2004, p. 33).

Essa compreensão conduz o debate sobre os rumos da Educação Especial no Brail, tornando-se fundamental para a construção de políticas de formação docente, financiamento e gestão escolar, necessárias para a transformação da estrutura educacional a fim de assegurar as condições de acesso, participação e aprendizagem de todos os estudantes, concebendo a escola como um espaço que reconhece e valoriza as diferenças.

Logo, o respeito à diversidade, efetivado no respeito às diferenças, impulsiona ações de cidadania voltadas ao reconhecimento de sujeitos de direitos, simplesmente por serem seres humanos. Suas especificidades não devem ser elemento para a construção de desigualdades, discriminações ou exclusões, mas sim devem pautar as políticas afirmativas de respeito à diversidade, voltadas para a construção de contextos sociais inclusivos, cujo aspecto filosófico-ideológico se assenta na equiparação de oportunidades, direitos e deveres, em que todas as pessoas teriam condições de vida e chance de realizar seus projetos como parte do exercício de sua cidadania e em respeito à sua identidade.

\section{Considerações finais}

Esta pesquisa foi instigada pela reflexão que questionava como foi se constituindo a compreensão de Educação Inclusiva ao longo dos tempos no Brasil, considerando a influência ideológica dos documentos legais produzidos pelos organismos internacionais ONU, Unesco, OEA, Unicef e BM - a partir das primeiras décadas do século XX. Tal inquietação acadêmica fez emergir o interesse em compreender a História da Educação Inclusiva, em especial no que concerne à escolarização das pessoas com deficiência defendida em acordos e discussões internacionais. O objetivo, com efeito, foi desenvolver um histórico a respeito das políticas públicas internacionais de Educação Especial com ênfase nas mudanças paradigmáticas emergentes cronologicamente no Brasil.

Realizou-se uma pesquisa documental nos textos internacionais produzidos sobre os debates acerca da Educação Inclusiva, em especial para as pessoas com deficiência, dentre os quais, destacam-se: Convenção Interamericana para a Eliminação de Todas as Formas de Discriminação contra as Pessoas Portadoras de Deficiência; Declaração Universal dos Direitos Humanos, A Unesco e a Educação na América Latina e Caribe (1987-1997); Educação para Todos: o Compromisso de Dakar; A Unesco no Brasil: Consolidando 
Compromissos; Conferência Mundial de Necessidades Educativas Especiais: Acesso e Qualidade. Os resultados permitiram desenvolver uma cronologia histórica, a qual possibilitou afirmar que os séculos XVIII e XIX foram marcados pela segregação homogeneizante das pessoas com deficiência em escolas especiais com edificação específica, que separavam os ditos estudantes "normais" dos alunos que possuíam algum tipo de limitação, período em que os debates sobre inclusão não possuíam ênfase no cenário internacional. A partir das primeiras décadas do século $X X$, os debates internacionais a respeito da escolarização dos então denominados discentes "especiais" foram se alargando; emergiram, em congruência, as classes especiais no interior das escolas regulares. Posteriormente, na segunda metade do século XX, os debates internacionais começaram a sinalizar a superação de qualquer forma de segregação e a impulsionar a ideologia atualmente defendida de igualdade e inclusão social com respeito às diferenças.

Ao fazer um balanço histórico sobre as políticas públicas de Educação Especial no cenário internacional, percebeu-se a ausência de documentos específicos nos séculos XVIII, XIX e início do XX. Somente ao longo dos séculos XX e XXI, especialmente nas décadas que seguem 1970, averiguou-se que a atuação das agências especializadas da ONU, em parceria com outras agências internacionais, governos, organizações não governamentais e sociedades civis, contribuiu de maneira importante para a transição do discurso educacional da integração instrucional para a constituição de saberes e práticas da Educação Especial sob a ótica inclusiva, ao desempenhar um fundamental papel como foro permanente de debate educacional e busca de soluções, contribuindo para a consolidação de uma agenda educacional e para a promoção da cooperação internacional e horizontal, com o objetivo de apoiar os processos de mudança das condições de vida das pessoas com deficiência, dentre elas a inclusão dessas pessoas nos espaços regulares de ensino em equiparação de oportunidades, direitos e deveres com relação aos seus pares sem deficiência.

A proposta global das Nações Unidas visava à promoção de uma Educação para todos ao longo de toda a vida, notadamente para grupos historicamente excluídos, como o das pessoas com deficiência. Para tanto, durante toda a década de 1990, houve uma expansão de acordos internacionais e uma redescoberta da Educação Especial como campo fértil de investimentos. Ocorreu a definição de uma agenda internacional para a Educação Especial, materializada em diferentes eventos, tais como: a Conferência Mundial sobre Educação para Todos (1990), a Declaração de Salamanca (1994), a Convenção da Guatemala (1999), o Compromisso de Dakar (2000) e a Convenção sobre os Direitos das Pessoas com 
Deficiência (2006), que trataram de pautas de interesses ordinários à comunidade internacional sobre o tema da Educação Especial em uma perspectiva de Educação Inclusiva.

Essas declarações e recomendações, resultantes das diferentes cúpulas, conferências e eventos regionais e internacionais, foram importantes para a construção de consensos em torno das principais ideias e propostas sobre Educação Especial nas décadas de 1980, 1990 e 2000, ou seja, da transição do modelo integracionista para o inclusivo. Nesses eventos, ao se constituírem em fóruns gerais, propalava-se a necessidade de reformas educativas nacionais acompanhadas de mudanças no financiamento, transformação curricular e gestão educacional em torno de sistemas educacionais inclusivos, perseguidos também no início do século XXI, que influenciaram a mudança de paradigma acerca do atendimento à pessoa com deficiência no Brasil.

No paradigma da inclusão, impulsionaram-se projetos de mudanças nas políticas públicas brasileiras, ao conceber-se que todos se beneficiam quando as escolas promovem respostas às diferenças individuais dos estudantes. Logo, a Educação Especial, que surgiu no campo da Pedagogia como uma área de conhecimento que se ocupava exclusivamente do processo de escolarização pela via da homogeneização dos alunos "excepcionais" em espaços escolares ditos "especiais", que orbitavam à margem do sistema de ensino público e gratuito, passou a integrar os tempos e espaços das escolas regulares, mas ficando a participação circunscrita às "classes especiais" e ainda sendo modalidade substitutiva e normalizadora do processo de escolarização dos discentes "portadores de necessidades especiais". Atualmente, sob a perspectiva da Educação Inclusiva, o Brasil tem como imperativo ético, normativo e intelectual ampliar a participação de todos os estudantes nos estabelecimentos de ensino regular, especialmente daqueles grupos sociais historicamente excluídos da escola, como as pessoas com deficiência, através de uma abordagem humanística e democrática, que perceba o sujeito e suas singularidades tendo como objetivos o crescimento, a satisfação pessoal e a inserção social de todos.

\section{Referências}

Brasil. Poder Executivo. (2001). Promulga a Convenção Interamericana para a Eliminação de Todas as Formas de Discriminação contra as Pessoas Portadoras de Deficiência. Decreto no 3.956. Brasil: Diário Oficial [da] República Federativa do Brasil.

Carvalho, Rosita Edler. (2002). A nova LDB e a Educação Especial (3ª ed.). Rio de Janeiro: WVA. 
Dechichi, Cláudia. (2001). Transformando o ambiente da sala de aula em um contexto promotor do desenvolvimento do aluno deficiente mental (Tese de Doutorado em Psicologia Educacional). Pontifícia Universidade Católica de São Paulo, São Paulo, Brasil.

Fávero, Osmar, Ferreira, Windyz, Ireland, Timothy e Barreiros, Débora. (2009). Tornar a Educação Inclusiva. Brasília: Unesco.

Mendes, Enicéia Gonçalves. (1995). Deficiência mental: a construção científica de um conceito e a realidade educacional (Tese de Doutorado em Psicologia). Universidade de São Paulo, São Paulo, Brasil.

Ministério da Educação. Secretaria de Educação Especial, Brasil. (2008). Política Nacional de Educação Especial na Perspectiva da Educação Inclusiva. Brasília: MEC. Recuperado de http://portal.mec.gov.br/arquivos/pdf/politicaeducespecial.pdf

Organização das Nações Unidas (ONU). (1948). Declaração Universal dos Direitos Humanos. Recuperado de http://unesdoc.unesco.org/images/0013/001394/139423por.pdf

Organização das Nações Unidas (ONU). (1975). Declaração dos Direitos das Pessoas Deficientes. Recuperado de http://portal.mec.gov.br/seesp/arquivos/pdf/dec def.pdf

Organização das Nações Unidas (ONU). (1981). Ano Internacional das Pessoas Deficientes. Resolução no $31 / 123$ aprovada pela Assembleia Geral da Organização das Nações Unidas em 16/12/76. Recuperado de http://www.dominiopublico.gov.br/download/texto/me002911.pdf

Organização das Nações Unidas (ONU). (1993). Normas sobre a Igualdade de Oportunidades para as Pessoas com Deficiência. Recuperado de http://www.inr.pt/uploads/docs/Edicoes

Organização das Nações Unidas (ONU). (2012). Convenção sobre os Direitos das Pessoas com Deficiência. Recuperado de http://www.pessoacomdeficiencia.gov.br/app/sites/default/files/publicacoes/convencaope ssoascomdeficiencia.pdf

Organização das Nações Unidas para a Educação, a Ciência e a Cultura, (Unesco). (1990). Conferência Mundial de Educação para Todos. Declaração Mundial de Educação para Todos. Plano de Ação para Satisfazer as Necessidades Básicas de Aprendizagem. Brasília: Unicef.

Organização das Nações Unidas para a Educação, a Ciência e a Cultura, (Unesco). (1994). Conferência Mundial de Necessidades Educativas Especiais: Acesso e Qualidade. Declaração de Salamanca sobre os Princípios, a Política e as Práticas na Área das Necessidades Educativas Especiais. Salamanca: Unesco.

Organização das Nações Unidas para a Educação, a Ciência e a Cultura, (Unesco). (1998). A Unesco e a Educação na América Latina e Caribe (1987-1997). Chile: Unesco. 
Organização das Nações Unidas para a Educação, a Ciência e a Cultura, (Unesco). (2001). Educação para Todos: o Compromisso de Dakar. Brasília: Consed.

Organização das Nações Unidas para a Educação, a Ciência e a Cultura, (Unesco). (2004). A Unesco no Brasil: consolidando compromissos. Brasília: Unesco.

Organização dos Estados Americanos, (OEA). (1999). Convenção Interamericana para a Eliminação de Todas as Formas de Discriminação contra as Pessoas Portadoras de Deficiência. Guatemala: OEA.

Peroni, Vidal. (2003). Política educacional e papel do Estado: no Brasil dos anos 1990. São Paulo: Xamã.

Rioux, Marcia e Valentine, Fraser. (2006). Does theory matter? Exploring the nexus between disability, human rights, and public policy. Em Dianne Pothier e Richard Devlin (Eds.), Critical disability theory: essays in philosophy, politics, policy, and law (pp. 47-69). Vancouver: The University of British Columbia.

Sánchez, Pilar Arnaiz. (2005). A Educação Inclusiva: um meio de construir escolas para todos no século XXI. Revista da Educação Especial, 7-18. Recuperado de http://portal.mec.gov.br/seesp/arquivos/pdf/inclusao.pdf

Sassaki, Romeu Kasumi. (2005). Inclusão: o paradigma do século 21. Revista da Educação Especial, 19-23.

Voivodic, Maria Antonieta Machado de Almeida. (2004). Inclusão escolar de crianças de crianças com Síndrome de Down (2ª ed.). Petrópolis: Vozes. 